\title{
ОСОБЕННОСТИ МОТИВАЦИИ ОБУЧЕНИЯ ИНОСТРАННЫМ ЯЗЫКАМ
}

\author{
Калерия Ковалёва, \\ Канд. филол. наук, Дочент кафедры иностранных языков и межкультурной коммуникации, \\ Харьковский национальный экономический университет имени Семёна Кузнеца, Украина, \\ Харьков \\ Эльвира Герасименко, \\ Ст. преподаватель кафедры иностранных языков и межкультурной коммуникации, \\ Харьковский нацииональный экономический университет имени Семёна Кузнецуа, Украина, \\ Харьков
}

DOI: https://doi.org/10.31435/rsglobal_ws/30042020/7031

\section{ARTICLE INFO}

Received: 14 February 2020

Accepted: 10 April 2020

Published: 30 April 2020

\section{KEYWORDS}

motive,

intrinsic / extrinsic motivation, anti-motivation, motivating factors, educational process.

\begin{abstract}
The problems and the specifics of motivation during foreign languages teaching in higher educational establishments have been considered in the article. The importance of this problem solving is determined by the fact that educational motivation is a decisive factor of educational process efficiency. Motivation provides interest to learning activity, improves the work of all cognitive mechanisms and speech activity: memory, thinking, attention and also activates the linguistic unit memorization, which stimulates successful foreign language communication. The aim of our investigation is to analyse the nature, structure and approaches of the motivation formation, development and maintenance during foreign languages studying. The object of our investigation is the educational activity motivation, in particular foreign languages teaching. The subject of our investigation is the structure, components, mechanisms of effective functioning, conditions of motivational studying activity development. Different classifications of motivational factors have been considered and the main types of motives during a foreign language studying have been distinguished. The anti-motivation factors which affect the quality of the educational process have been also considered in the context of this work. As a result of investigation, it has been stated that the level of motivation increasing during a foreign language studying is possible only with the complex usage of these conditions.
\end{abstract}

Citation: Калерия Ковалёва, Эльвира Герасименко. (2020) Osobennosti Motivacii Obucheniya Inostrannym Yazykam. World Science. 4(56), Vol.3. doi: 10.31435/rsglobal_ws/30042020/7031

Copyright: (C) 2020 Калерия Ковалёва, Эльвира Герасименко. This is an open-access article distributed under the terms of the Creative Commons Attribution License (CC BY). The use, distribution or reproduction in other forums is permitted, provided the original author(s) or licensor are credited and that the original publication in this journal is cited, in accordance with accepted academic practice. No use, distribution or reproduction is permitted which does not comply with these terms.

Введение. Проблема мотивации является одной из фундаментальных проблем современного образовательного процесса и доминирующих, в частности, в процессе обучения иностранному языку, так как знание иностранного языка - свидетельство уровня культуры и образования. Процесс глобализации в сфере высшего образования акцентирует внимание на мотивации в изучении иностранных языков, так как сфера их применения для современного человека значительно расширяется с увеличением международных связей, установлением культурных контактов, а также возможностью получения информации на иностранном языке. Формирование, развитие, повышение мотивации учебной деятельности, использование технологий обучения, основанных на понимании механизмов функционирования мотивационных составляющих, сможет существенно повысить эффективность учебного процесса и позволит достичь высокого уровня результатов - этим и определяется актуальность данного исследования. 
Объектом исследования является мотивация учебной деятельности, в частности обучения иностранным языкам.

Предмет исследования: структура, составляющие, механизмы эффективного функционирования, условия развития мотивационной учебной деятельности.

Сложность и многоаспектность проблемы мотивации обуславливает множественность подходов к пониманию её сущности, природы, структуры, а также к методам её изучения. Проблема развития мотивации учебной деятельности рассматривалась в трудах Л. Божович, В. Боровского, В. Ведзинской, Н. Войтониса, В. Вундта, Э. Галажинского, Э. Зеера, И. Идинова, В. Ковалева, Е. Кузьмина, Н. Ланге, В. Мерлина, К. Платонова, К. Роджерса, С. Рубинштейна, П. Рудика, А. Смирнова, А. Степанова, Д. Узнадзе и др. В работах Р. Вайсмана и др. уделяется внимание профессиональной направленности обучения в вузах и на этой основе разрабатываются целевые установки студентов, фиксирующие, какую мотивацию воспитать у будущих специалистов. В работах К. Левина, А. Маслоу, Г. Олпорта и др. изучается мотивация самоактуализации человека.

Проблема мотивации изучения иностранных языков отражена в работах Э. Вертоградской, И. Зимней, С. Дороховой, Ю. Нефедовой, С. Хаврониной и других ученых. В них описываются мотивы изучения иностранных языков и основные мотивоформирующие факторы, рассматриваются методы повышения мотивации.

Однако в ситуации сокращения аудиторных часов, соответственно увеличения значимости самостоятельной работы студентов, и в связи с необходимостью перехода на дистанционную форму обучения проблема формирования и повышения мотивации остается попрежнему актуальной и требует дальнейшего изучения.

В современных условиях развития многоуровневого, интегративного, многоступенчатого образования приоритетной задачей высших учебных заведений является возможность научить студента самостоятельно приобретать знания, способствующие личностному росту. Для того чтобы деятельность стала компонентом развития и саморазвития нужно постоянно совершенствовать мотивационную сторону личности. Мотивация является «запускным механизмом» (И. Зимняя, 1978) успешного обучения любым предметам, в частности, иностранным языкам. Формирование адекватной образовательной мотивации студентов существенно повышает успех профессиональной подготовки.

Целью нашего исследования является анализ сущности, структуры и подходов формирования мотивации учебной деятельности в условиях возросшей потребности быстрого и качественного обучения иностранному языку.

Результаты исследования. Впервые дефиниция «мотивация» появилась в статье А. Шопенгауэра «Четыре принципа достаточной причины» (1900-1910 г.г.), впоследствии этот термин прочно вошёл в психолого-педагогический обиход.

Современное состояние исследований мотивации характеризуется множеством концепций и теорий, разрозненностью теоретических представлений, выраженным терминологическим разнообразием. Так, мотивация понимается как совокупность факторов, детерминирующих, организующих и направляющих поведение человека (система потребностей, мотивов, целей, намерений, идеалов, убеждений и мн. др.) (К. Мадсен [К. Madsen, 1959]; Ж. Годфруа, 1992), как совокупность устойчивых мотивов, побуждений, которые определяют содержание, направленность и характер деятельности личности, её поведение» [10, с. 216], как вербальное поведение, направленное на выбор мотивов (суждений) для объяснения, обоснования реального трудового поведения (В. Адамчук, О. Ромашов, М. Сорокина, 2000).

Таким образом, исследователи выделяют два направления изучения мотивации: первое рассматривает мотивацию со структурных позиций, как совокупность факторов или мотивов, второе - как динамичное образование, как процесс, механизм. Но в обоих случаях мотивация выступает как вторичное по отношению к мотиву образование, явление, как процесс регуляции деятельности с помощью мотива.

Также нет единого сложившегося мнения в понимании соотношений между мотивацией и мотивом. Во многих работах эти два понятия используются как синонимы. В самом общем плане мотив (от франц. motif - побудительная причина, повод) - это «побуждение к деятельности, связанное с удовлетворением потребностей человека; совокупность внешних и внутренних условий, вызывающих активность субъекта и определяющих её направленность» 
[1, с. 237], «это то, что объясняет характер данного речевого действия, тогда как коммуникативное намерение выражает то, какую коммуникативную цель преследует говорящий, планируя ту или иную форму воздействия на слушающего» [5, с.18].

В соответствии с концепцией А. Н. Леонтьева (1971), которому принадлежит одна из наиболее оформленных теорий мотивации, мотивы рассматриваются как опредмеченные потребности, означающие то объективное, в чем эта потребность конкретизируется в данных условиях и на что направляется деятельность, побуждающая её. Сущность мотивации А. Н. Леонтьев рассматривает как предмет, отвечающий данной потребности [11].

Мы, вслед за Т. О. Гордеевой, понимаем мотивацию учебной деятельности как системное образование, обеспечивающее побуждение, направленность и регуляцию выполнения учебной деятельности [3]. Таким образом, мотивация выполняет роль движущей силы академических достижений.

Под мотивом учебной деятельности мы понимаем все факторы, обусловливающие проявление учебной активности: потребности, цели, установки, намерения, стимулы, чувство долга, интересы и т. д.

Учебная деятельность, как и любая другая, побуждается разного рода факторами (мотивами). Так, Г. Розенфельд, (G. Rosenfeld, 1973) выделил следующие контент-категории (факторы) мотивации учения:

1. Обучение ради обучения, без удовольствия от деятельности или без интереса к преподаваемому предмету.

2. Обучение без личных интересов и выгод.

3. Обучение для социальной идентификации.

4. Обучение ради успеха или из-за боязни неудач.

5. Обучение по принуждению или под давлением.

6. Обучение, основанное на понятиях и моральных обязательствах или на общепринятых нормах.

7. Обучение для достижения цели в обыденной жизни.

8. Обучение, основанное на социальных целях, требованиях и ценностях.

Как видим, в данной классификации в подавляющем большинстве выделены факторы, отражающие окружающий мир, а не связанные непосредственно с личностью.

Тогда как А. Печников и Г. Мухина (А. Печников, Г. Мухина, 1996) ведущими учебными мотивами у студентов называют «профессиональные» и «личного престижа», менее значимы «прагматические» (получить диплом о высшем образовании) и «познавательные». Исследователи отмечают, что на разных курсах роль доминирующих мотивов меняется. На первом курсе ведущий мотив - «профессиональный», на втором - «личного престижа», на третьем и четвертом курсах оба этих мотива, на четвертом - еще и «прагматический». На успешность обучения в большей степени влияли «профессиональный» и «познавательный» мотивы. «Прагматические» мотивы были в основном характерны для слабоуспевающих студентов.

В работе В. Молчановского и Л. Шипелевич выделены собственно учебные мотивы (связанные с содержанием учебного предмета и с процессом обучения) и внеучебные мотивы (широкие социальные мотивы, личные мотивы, отрицательные мотивы). На отрицательных мотивах мы остановимся ниже более подробно.

Многие исследователи условно подразделяют мотивацию учебной деятельности на внутреннюю и внешнюю, с точки зрения лежащих в их основе базовых потребностей. При этом важно отметить, что разделить мотивы четко на две группы представляется очень сложным.

Так, составляющими внутренней мотивации («мотивы смыслообразующие» по А. Леонтьеву, 1971) являются базовые потребности индивида в познании, саморазвитии, удовлетворении, удовольствии от процесса познания и достижения результата, энтузиазме и увлеченности учебным процессом. Внутренняя мотивация связана не с внешними обстоятельствами, а непосредственно с самим предметом изучения - «я хочу знать изучаемый язык, чтобы читать, выражать свои мысли и вступать в коммуникацию с носителем данного языка» [3]

Внешняя мотивация («мотивы-стимулы» по А.Н. Леонтьеву, 1971) представляет собой «неоднородное образование, задаваемое двумя качественно разными типами учебных мотивов, одни из которых соответствуют удовлетворению базовых потребностей личности в самоуважении, уважении и признании значимыми другими, а другие являются результатом 
фрустрации базовых психологических потребностей в автономии, компетентности и принятии и оказывают негативное влияние на другие мотивационные переменные и непосредственно на успешность учебной деятельности ...» [3].

При обучении иностранным языкам мотивация приобретает совершенно иное значение, задействованы другие психологические образования, порождающие активность. Это обусловлено спецификой данного учебного предмета.

Важно отметить, что стратегической целью обучения иностранному языку является формирование вторичной языковой личности, в полной мере владеющей коммуникативной компетенцией как способностью решать коммуникативные задачи языковыми средствами на достаточно высоком уровне [16, с. 109]. В завершении учебного процесса студент способен вести коммуникативную деятельность средствами изучаемого языка. Именно благодаря наличию этой цели мотивация, как внутренняя, так и внешняя, приобретает определенный смысл. Задача преподавателя состоит в том, чтобы повысить мотивацию к овладению предметом, сделать так, чтобы интерес к нему был постоянным и устойчивым. Если обучающимся интересно на занятиях, если они ощущают необходимость того, что они изучают, то у них лучше работают все механизмы когнитивной и речевой деятельности: память, мышление, внимание. У обучающихся повышается работоспособность, они быстрее усваивают учебный материал. Это означает, что высокая мотивация является еще и важным фактором интенсификации обучения.

В своей работе О. Фомберг, Л. Печеникова, И. Луговскова выделяют следующие мотивы изучения иностранного языка:

1. общение как социально-культурная потребность человека;

2 долгосрочные планы, связанные с построением семьи или бизнеса;

3. профессиональная и образовательная ориентация;

4. любовь к языку и желание интеллектуального роста;

5. атмосфера благоприятного общения на занятии и любовь к своему преподавателю;

6. доступ к средствам массовой информации;

7. знание языка как основного средства межкультурного общения;

8. трудности, вызывающие напряженную работу познавательных сил;

9. получение положительной оценки как внешний, но необходимый фактор при оценивании знаний и умений студентов [12].

Канадские психологи Р. Гарднер и У. Ламберт выделили две группы мотивации обучения иностранному языку: интегративную и инструментальную.

Интегративная мотивация основана на получении новых знаний в рамках изучения иностранного языка, в процессе взаимодействия преподавателя и студентов, когда обучаемый хочет стать частью иноязычной культуры, овладеть иностранным языком, понимать его и свободно общаться с носителями языка, получить определённый статус в обществе. У студентов формируется долговременный интерес к иноязычной культуре, открываются возможности для саморазвития и самореализации. Это отражает внутреннюю мотивацию.

Инструментальная мотивация базируется на практической цели - получение диплома / сертификата, учёба в зарубежном вузе, получение более престижной работы, а также интерес к изучению иностранного языка под положительным воздействием педагога [4, с. 167], что соответствует внешней мотивации. На наш взгляд личностные качества преподавателя являются немаловажным мотивационным фактором. Так как умение создать благоприятный микроклимат в группе, атмосферу взаимоуважения и взаимопонимания, установление доверительных и дружеских отношений, индивидуальный подход к интересам и потребностям каждого студента, способствуют успешному развитию коммуникативных навыков. Результатом такой мотивации является успешное овладение иностранным языком.

Для успешного изучения иностранного языка необходимо, конечно же, наличие обоих видов мотивации.

При внешней мотивации на человека действуют те факторы, которые находятся в окружающем его мире, вне его личности. Этим факторам зачастую может служить общественное мнение, от которого, так или иначе, зависима любая личность. Нас мотивируют родители, педагоги; они побуждают нас к действиям, которые мы выполняем, чтобы получить награду или избежать наказания, когда обучение выполняется в силу давления родных, преподавателей. Соответственно, этот вид мотивации делится на позитивную и негативную. В первом случае человека мотивируют 
тем, что он получит при выполнении этой работы какое-либо вознаграждение, похвалу. А во втором - отрицательными последствиями за невыполнение этой работы. Именно тем, ради чего мы совершаем то или иное действие, и отличается внешняя мотивация от внутренней. При втором виде мотивации человек совершает те действия, которые приносят ему личную пользу.

Внутренняя мотивация побуждает заниматься человека делом, не потому что он получит вознаграждение за проделанную работу, а потому что ему нравится этим заниматься, потому что он получает удовольствие от процесса или его результата. Факторы, действующие на человека, находятся внутри него; это его мысли и чувства. Эти виды мотивации по-разному влияют в той или иной ситуации, поэтому нельзя сказать какая мотивация сильнее. Эти виды мотивации идут раздельно, но именно с помощью внешней мотивации есть шанс натолкнуть личность на внутреннюю: внешняя мотивация к выполнению дела, изначально не привлекательного для определенного человека, может послужить толчком к развитию внутренней мотивации в связи с эмоциональной реакцией на достижения, оцененные извне [13, 874-877]. Формирование внутренней мотивации является необходимым условием успешной деятельности в любой сфере. Взаимодействие всех этих факторов формирования учебной мотивации оказывает влияние на характер учебной деятельности и ее результаты.

Исследователь А. Айтпаева выделяет наиболее эффективные методы стимулирования и мотивации при обучении, а именно, эмоциональные, социальные и познавательные методы.

Так, к эмоциональным методам автор относит:

1. поощрение/порицание (большей частью поощрение, поддержку, так как негативная оценка речевого действия слабого студента может привести к нежелательным реакциям с его стороны);

2. создание ярких наглядно-образных представлений (использование яркой, интересной наглядности, просмотр видеофильма, мнемонические фразы, карты);

3. создание ситуаций успеха (распределение заданий с учётом способностей студентов и их психологических и национальных особенностей);

4. свободный выбор заданий (предоставить возможность выбора для студентов).

К социальным методам относятся:

1. побуждение не отставать от сильного студента (формировать пары для работы «сильный + слабый студент»);

2. создание ситуаций взаимопомощи (студенты помогают друг другу с объяснением).

Познавательные методы включают:

1. учебно-познавательные игры (различные виды ролевых заданий);

2. создание проблемных ситуаций, использование механизма провокации (дискуссии, разработка проектов);

3. выполнение творческих заданий (работа над докладами и презентациями по разным темам, написание сочинений, самостоятельная подготовка к экскурсиям по городу и т.д.) [2].

Используя накопленный педагогический опыт, мы применяем на занятиях по иностранному языку следующие методы стимулирования учебной деятельности:

1. применение интерактивных методов преподавания (обучение в сотрудничестве, проблемное предъявление материала, решение проблемных дидактических задач, тематические дискуссии с использованием мозгового штурма, включение студентов в коммуникативные речевые ситуации, ролевые и деловые игры, устные и письменные учебно-дидактические игры, творческие конкурсы, конференции, олимпиады, использование кейс- и квест- методов, метод проектов);

2. использование информационных компьютерных технологий (материалы различных сайтов Интернета, сайт учебного заведения, компьютерные обучающие программы и игры, программы для создания интерактивных тестов и заданий, мультимедийные ресурсы: музыка, песни, стихи, фильмы, использование компьютерных программ для создания презентаций, слайд-шоу, видео, схем, анимации и т.д.)

3. использование приемов-стимулов, создающих условия для продуктивного овладения речевыми навыками: «разогрев» - подготовка к речи (фонетическая, лексико-грамматическая, интонационная зарядка, снежный ком, ассоциативный ряд), ментальные карты, рабочие листы, кластер, кроссенс, синквейн, тексты-каркасы, вербально-графический план, ассоциативное облако, инфографика, мемы, скрайбинг.

4. привлечение лингвострановедческого материала (моделирование учебных текстов и материалов страноведческого содержания, знакомство с культурой, мировоззрением, 
ментальностью страны и народа изучаемого языка, национальными традициями, праздниками и обычаями, участие в них, проведение экскурсий);

5. использование межпредметных связей (проведение интегрированных и бинарных уроков, тематических занятий с привлечением представителей других учебных групп, курсов, факультетов или других учебных учреждений);

6. создание благоприятной атмосферы общения (поощрения, использование дополнительных средств общения (телефон, соцсети, чаты, почта и т.д.), дополнительные внеаудиторные занятия, направленные на развитие коммуникативных компетенций, расширение круга общения);

7. развитие навыков самостоятельной работы студентов (самоконтроль и самооценка, использование силлабуса, портфолио, индивидуальные консультации, смешанное обучение);

8. активная позиция преподавателя (обучение на собственном примере, творческий подход к работе, повышение уровня профессионализма (непрерывное образование), создание педагогических условий, способствующих формированию положительной мотивации, разработка и внедрение комплекса педагогических средств, способствующий развитию мотивации в изучении иностранного языка).

Существенным мотиватором в учебном процессе, а особенно при изучении иностранного языка, является преподаватель, роль которого трудно переоценить. Хотелось бы подробнее остановиться на данном факторе мотивации.

Ведущую роль в формировании общекультурных и общепрофессиональных компетенций будущего конкурентоспособного специалиста приобретают профессиональные и личностные качества преподавателя. На сегодняшний день актуальными профессиональными критериями являются наличие профильного образования, допустимый педагогический стаж, ученая степень (звание), наличие сертификата о повышении квалификации, публикационная активность (статьи ВАК, Web of Science, Scopus), научные изыскания, учебные пособия, монографии и другое.

Но помимо профессиональной компетенции преподаватель должен обладать определенным набором личностных качеств: трудолюбие, добросовестность, личная дисциплинированность, активность, креативность, артистизм, юмор, уважительное и толерантное отношение к коллегам и студентам, терпимость к критике и способность к самоанализу и самокритике.

Личностные качества формируют харизму, обаяние преподавателя. И благодаря этой харизме, а также профессионализму и любви к предмету, преподаватель способен мотивировать студентов к изучению своей дисциплины, причем эта мотивация, порой, оказывается сильнее мотивации от прагматической ценности самого изучаемого предмета. Ведь в условиях личностноориентированного подхода к организации процесса обучения, при использовании современных образовательных технологий роль преподавателя очень изменилась: он выступает как консультант и помощник, оказывающий психосоциальную, информационную и техническую поддержку, дающий методические рекомендации по работе с учебными материалами, выступает как посредник, передающий необходимую информацию. Одним словом, задача преподавателя не столько в том, чтобы транслировать готовые знания студенту, сколько в том, чтобы организовывать их самостоятельную образовательную деятельность, формировать их внутреннюю мотивацию к изучению дисциплины, способствовать совершенствованию личностных и профессиональных качеств будущих специалистов.

На занятиях по иностранному языку партнерские отношения особенно важны, так как основной целью обучения иностранным языкам является формирование и развитие коммуникативной компетенции студентов, обучение практическому овладению иностранным языком; а основной формой приобщения обучающихся к коммуникации на иностранном языке выступает продуктивный диалог с преподавателем, выступающим своеобразным посредником между культурами. Научиться говорить на иностранном языке можно только общаясь, поэтому первоочередной задачей преподавателя иностранного языка (и при этом едва ли не самой сложной) является создание на занятии атмосферы общения.

Однако, все попытки преподавателя осуществить это будут безуспешными, если студента не интересует преподаватель как личность, как речевой партнер. Успешная реализация целевых установок обучения иностранному языку во многом зависит от уровня 
профессионального мастерства преподавателя. Обладая всесторонними лингвистическими знаниями, хорошей методической подготовкой, преподаватель иностранного языка выступает в роли речевого партнера, способного передать свою влюбленность в язык, который он преподает, в культуру, которую этот язык представляет. Преподаватель должен быть способен создать такую атмосферу доверия и комфортности, которая способствовала бы раскрепощению обучающихся, преодолению языкового барьера, чувства неуверенности, появлению желания общаться, делиться своими мыслями. Следовательно, задача преподавателя - найти оптимальные варианты (мотивационные условия) для достижения поставленных целей в максимально благоприятной эмоциональной обстановке.

В контексте данного исследования считаем необходимым остановиться еще на одном немаловажном аспекте изучения феномена мотивация. На сегодняшний день основной акцент при исследовании данной категории делается на её положительной стороне. Однако «низкая или недостаточная мотивация учения может быть обусловлена не только несформированностью собственно мотивов учения, сколько сформированностью таких образований, которые имеют по отношению к ней «антимотивационную» направленность. В результате чего в структуре мотивационной сферы может формироваться достаточно сильный и устойчивый комплекс антимотивационных факторов» [7]. В этом случае под антимотивами понимается не недостаточный уровень развития каких-либо учебных мотивов, а высокий уровень иных мотивационных образований, которые препятствуют осуществлению учебной деятельности. При этом подобные мотивы не обязательно будут отрицательными. Например, увлечение спортом или общественной работой само по себе не имеет никакой отрицательной функции, а скорее наоборот. Но неправильно расставленные приоритеты могут мешать качественной и эффективной учебной деятельности. В то же время такие антимотивы как лень, отсутствие желания в отношении учебы, неприязнь к преподавателю или конфликты в коллективе несут абсолютно отрицательное содержание. Поэтому мы можем говорить об относительности оценки антимотивации, о сочетании в ней негативных и позитивных мотивов.

В настоящее время содержание понятия «антимотивация» остается достаточно общим, неопределенным, достаточно широким, а состав антимотивов - очень гетерогенным. По мнению Е.В. Карповой, антимотив - это не «не-мотив» (т. е. фактически отсутствие мотива); это - именно мотив, но как бы с «обратной направленностью», с «противоположным зарядом» по отношению к учебной деятельности [8]. Исследовательница предлагает, как нам кажется, оправдано, дифференцировать это понятие на антимотивы в узком и в широком смыслах: на собственно антимотивы и на то, что может выступать в функции антимотивов. В узком смысле под антимотивами следует понимать те мотивационные факторы, которые имеют прямую негативную направленность по отношению к учебной деятельности. Это, например, убеждения о «ненужности» тех или иных учебных предметов и, соответственно, негативная мотивационная направленность по отношению к их усвоению. Состав антимотивов в широком смысле гораздо шире. Так, в функции антимотивов может выступать низкий уровень сформированности позитивных учебных мотивов, поскольку общий мотивационный потенциал учебной деятельности будет снижаться, а сами они по отношению к данному потенциалу будут играть именно негативную роль. Таковыми, например, могут быть динамические тенденции, которые возникают под влиянием негативных реакций на многочисленные внешние, принудительные, воздействия со стороны родителей, учителей, социальной микросреды, всей организации этой деятельности.

Каковы же основные факторы антимотивации, их содержание и частотность? Как нам кажется, единой однозначной классификации этого явления быть не может. Ведь эти факторы будут зависеть от многих, например, в какой аудитории (возраст, образование, профессия, социальный статус, семейное положение, национальность и др.) они будут выявляться, по отношению к какой учебной деятельности будет проводиться исследование и т.д. Так, в работах Н. Ивановой, Е. Минаевой, Ю. Козубай, Ю. Шмаковой, Л. Коробовой $[6 ; 9 ; 14]$ были выделены 6 групп антимотивационных факторов, в каждую из которых вошли по 5 факторов, отнесённые либо к основным структурным компонентам образовательной среды:

1. пространственно-предметному (интерьер, эстетика, комфорт, методическое и техническое обеспечение учреждений образования);

2. психодидактическому (содержание и качество обучения (концепции, программы), методы и технологии обучения); 
3. социальному (психологический комфорт во взаимоотношениях студент-студент, студент-преподаватель);

4. субъектному (личностные качества обучаемого), либо к микросреде (моральные и материальные семейные ценности) и макросреде (общество в целом: ценность образования, рейтинг профессии, заработная плата и т.д.).

Кроме того, исследования показали, что количественное и качественное соотношение антимотивационных факторов в разных средах меняется, но, как правило, наиболее значимыми являются факторы, связанные с психодидактическим и социальным компонентами. То есть на первый план выходят антимотивы, которые отражают качество получаемых знаний, например, однообразные, традиционные формы и методы проведения занятий, большой объем общих теоретических дисциплин и материала для самостоятельного изучения, недоступное объяснение материала; а также антимотивы, связанные с психологическими взаимоотношениями в группе, например, необъективность (предвзятость) преподавателей в оценке знаний студентов или отсутствие контакта, конфликты с преподавателями и соучениками. Факторы, связанные с макро- и микросредой оказались не столь важными, за исключением их материальной составляющей (необходимость зарабатывать деньги и низкая заработная плата будущей профессии).

Считаем необходимым подчеркнуть, что изучение проблемы антимотивации и содержания антимотивационных факторов, влияющих на качество образовательного процесса, поможет организовать обучение эффективно, используя приёмы мотивации и нивелируя факторы антимотивации.

Выводы. Таким образом, первоочередной задачей современного образовательного процесса является не только передача информации, но и мотивирование студентов на учебнопознавательный процесс, на самообразование, на обучение самостоятельной и регулярной работе. Следует учитывать, что при формировании мотивации играют роль разные аспекты, а именно: конкретная социально-политическая ситуация в стране изучения иностранного языка, особенности родного языка и родной культуры обучающихся, национальные лингводидактические традиции, национальная специфика мотивационной сферы личности, объективные факторы: возраст, пол, способность, эмоциональная устойчивость, современные педагогические технологии (ИКТ), количество учебных аудиторных часов (абсолютный переход на дистанционное обучение, связанный с форс-мажорными обстоятельствами в мире, оказался недостаточно эффективным для обучения в группах и применим в технологиях смешанного обучения), а также профессиональные и личностные качества преподавателя. Обучение языку - долгий, тернистый путь, в котором преподаватель является основным мотиватором.

Повышение уровня мотивации в процессе изучения иностранного языка возможно исключительно при комплексном использовании этих условий.

Перспективой нашего исследования является сравнительный анализ путей формирования мотивации изучения иностранного языка в разных странах мира, а также более глубокое исследование проблем антимотивации. Подобные исследования необходимы для определения наиболее качественных, эффективных и точных методов и приёмов мотивации.

\section{ЛИТЕРАТУРА}

1. Азимов Э. Л., Щукин А. И. Словарь методических терминов: теория и практика преподавания языков. СПб., 1999. $471 \mathrm{c.}$

2. Айтпаева А. С. Методы мотивации и стимулирования в преподавании РКИ: их роль и возможности. URL: http://pps.kaznu.kz/ru/Main/FileShow2/15233/38/2/1/0/.

3. Гордеева Т. О. Мотивация учебной деятельности школьников и студентов: структура, механизмы, условия развития. Автореф дисс. ... доктора психол. наук: 19.00.07. М., 2013. 35 с. URL: https://www.dissercat.com/content/motivatsiya-uchebnoi-deyatelnosti-shkolnikov-i-studentov-strukturamekhanizmy-usloviya-razvi/read.

4. Данилова О. А., Конова Р. А. Дукин Д. В. Роль мотивации в изучении иностранных языков М.: АРКТИ, 2000. С. 167-169.

5. Зимняя И. А. А. Педагогическая психология. - Ростов-на-Дону: Феникс, 1997. 480 с.

6. Иванова Н. В., Минаева Е. В., Козубай Ю. В. Проблема изучения антимотивации учебной деятельности у студентов педагогического университета. Вестник Минского университета. 2015. № 2. С. 67-74.

7. Карпова Е. В. Антимотивация в структуре учебной деятельности. Психология образования в XXI веке: теория и практика. URL: https://psyjournals.ru/education21/issue/54089_full.shtml

8. Карпова Е. В. Структура и генезис мотивационной сферы личности в учебной деятельности: дис. ... д-ра. психол. наук. Ярославль, 2009. 
9. Коробова Л. В. Иванова Н. В., Минаева Е. В. Средовой подход к диагностике антимотивации учебной деятельности у студентов педагогического вуза. Современные проблемы науки и образования. 2015. № 1. URL: http://www.science-education.ru/121-18338.

10. Кухаренко В. М., Березенська С. М., Бугайчук К. Л. та ін. Теорія та практика змішаного навчання. Монографія. Харків: Міськдрук, НТУ «ХПІ», 2016. 284 с.

11. Леонтьев А. Н. Потребности, мотивы и эмоции. М., 1971. 40 с.

12. Фомберг О. А., Печеникова Л. Н., Луговскова И. А. Мотивация студентов при изучении РКИ: проблемная ситуация и способы её решения. URL: http://dspace.nbuv.gov.ua/ bitstream/handle/123456789/92894/16-Fomberg.pdf?sequence=1.

13. Чуйко Т. А., Русскова Е. В. Виды работы, влияющей на мотивацию к изучению иностранного языка в неязыковом вузе. Молодой ученый. 2015. №7. С. 874-877. URL: https://moluch.ru/archive/87/16941.

14. Шмакова Ю. А, Иванова Н. В., Минаева Е. В. Проявления антимотивации учебной деятельности у студентов колледжа искусств. Современные наукоемкие технологии. 2016. № 3. Ч. 2. С. 382-385. URL : http://www.top-technologies.ru/ru/article/view?id=35755.

15. Шкиндер В.И. Проблема мотивации учебной деятельности студентов в условиях коммерциализации высшего профессионального образования. URL: http://do.teleclinica.ru/184374.

16. Щукин А. Н. Теория обучения иностранным языкам (лингводидактические основы). М., 2012. С. 109. 